\title{
What Can COVID-19 Teach Us about Using AI in Pandemics?
}

\author{
Krzysztof Laudanski ${ }^{1,2, *}$, Gregory Shea ${ }^{2,3}$, Matthew DiMeglio ${ }^{4}\left(0\right.$, Mariana Restrepo ${ }^{5}$ \\ and Cassie Solomon ${ }^{6}$ \\ 1 Department of Anesthesiology and Critical Care, Hospital of the University of Pennsylvania, \\ Philadelphia, PA 19104, USA \\ 2 Leonard Davis Institute of Health Economics, University of Pennsylvania, Philadelphia, PA 19104, USA; \\ sheag@wharton.upenn.edu \\ 3 The Wharton School, University of Pennsylvania, Philadelphia, PA 19104, USA \\ 4 Department of Internal Medicine, Thomas Jefferson University Hospital, Philadelphia, PA 19107, USA; \\ matthew.dimeglio@jefferson.edu \\ 5 Department of Biology, University of Pennsylvania, Philadelphia, PA 19104, USA; rmariana@sas.upenn.edu \\ 6 The New Group Organizational Consulting Inc., Philadelphia, PA 19104, USA; \\ cassie@thenewgroupconsulting.com \\ * Correspondence: krzysztof.laudanski@pennmedicine.upenn.edu; Tel.: +1-352-222-5202
}

Received: 23 October 2020; Accepted: 24 November 2020; Published: 1 December 2020

\begin{abstract}
The COVID-19 pandemic put significant strain on societies and their resources, with the healthcare system and workers being particularly affected. Artificial Intelligence (AI) offers the unique possibility of improving the response to a pandemic as it emerges and evolves. Here, we utilize the WHO framework of a pandemic evolution to analyze the various AI applications. Specifically, we analyzed AI from the perspective of all five domains of the WHO pandemic response. To effectively review the current scattered literature, we organized a sample of relevant literature from various professional and popular resources. The article concludes with a consideration of AI's weaknesses as key factors affecting $\mathrm{AI}$ in future pandemic preparedness and response.
\end{abstract}

Keywords: pandemic; COVID-19; artificial intelligence; demand constraints; innovation

\section{Background and Significance}

In December 2019, severe acute respiratory syndrome coronavirus 2 (SARS-CoV-2) was isolated from a series of pneumonia cases in Wuhan, China [1]. Extensive international spread has followed since then, causing millions of reported cases and hundreds of thousands of deaths to date [2]. The disease associated with this coronavirus infection (COVID-19) continues to strain healthcare systems and societies at large due to the disease virulence and morbidity [3,4]. History offers examples of pandemics that unfolded similarly to COVID-19, and the World Health Organization (WHO) created a framework describing distinctive intervals of an infectious outbreak (Figure 1) [5-8]. Initially, the "identification" of transmission of a novel virus, viral strain, or biological organism to humans must be identified. The "recognition" interval follows and features case clusters' identification globally. "Initiation" comes next and references the development of sustained human transmission. Next, case rates speed up during the "acceleration" interval concomitant with the deployment of several mitigation strategies. These efforts lead to the plateauing and subsequent decrease in case rates, which permits the international community to enter the next pandemic interval, "deceleration." As case rates finally slow, the international community enters the final interval, "preparation" (for the next pandemic wave) [8]. 


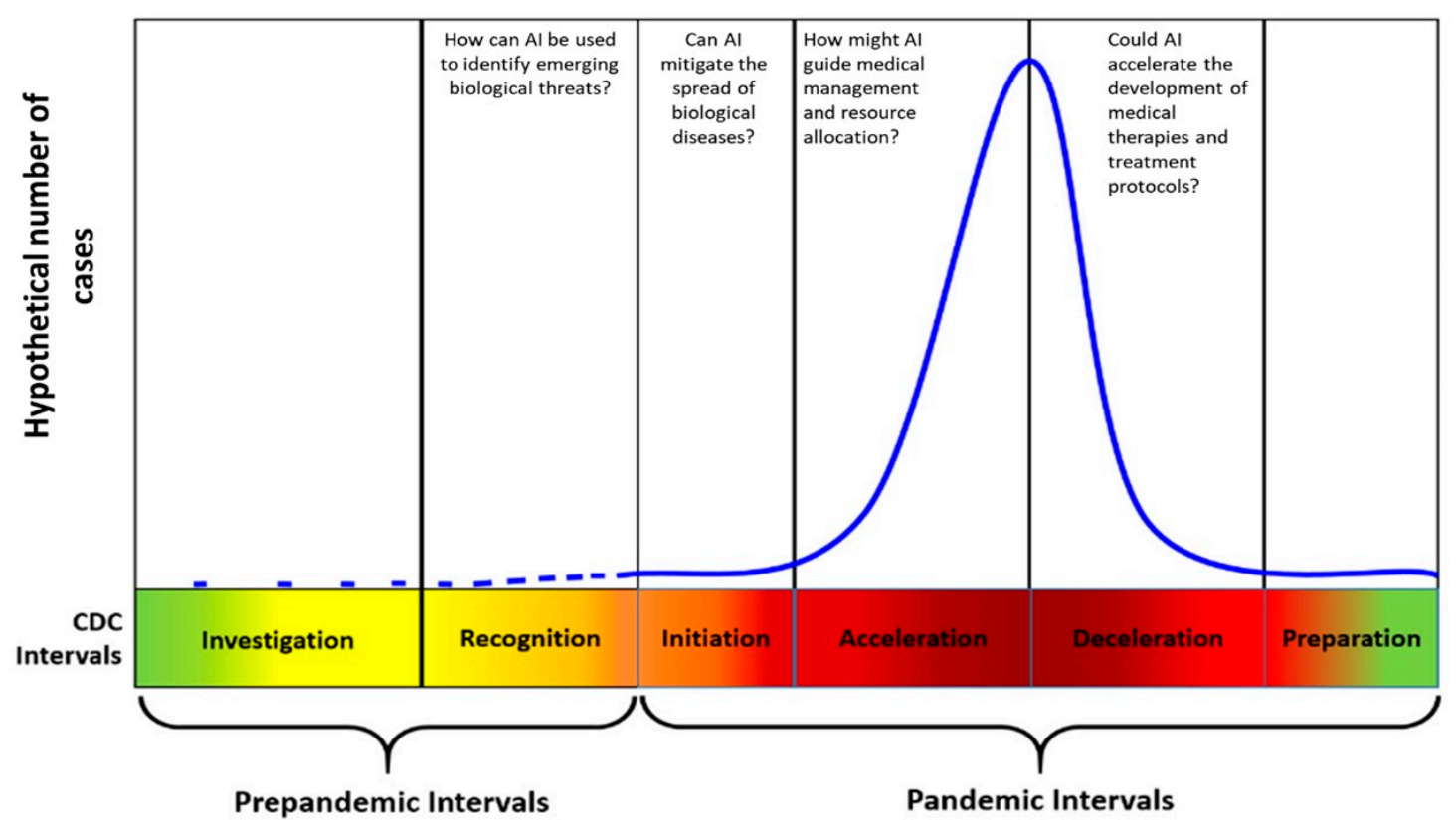

Figure 1. WHO pandemic response phases with distinctive AI applications.

Artificial intelligence (AI) contains the potential to address all these pandemic challenges, a fact slowly being realized by healthcare stakeholders [9-14]. In this manuscript, we will define the AI as algorithms built on mathematical models, themselves continuously and automatically refined through iteration within a "training dataset," that is, through a set of examples used to increase their prediction capabilities [10]. This article utilizes the WHO pandemic framework to organize consideration of four questions regarding $\mathrm{AI}^{\prime}$ 's qualifications in each of the pandemic's intervals: (1) how can AI be used to identify emerging biological threats? (2) Can AI mitigate the spread of biological diseases? (3) How might AI guide medical management and resource allocation? (4) How might AI accelerate the development of medical therapies and treatment protocols? This article concludes with a consideration of AI's weaknesses and then three questions about the overall future of $\mathrm{AI}$ in healthcare and pandemic response.

\section{Materials and Methods}

The authors employed the WHO framework to inform an Internet search using keywords from each pandemic interval (emergence, recognition, identification, mitigation, deceleration) on the cohort of 866 PubMed manuscripts obtained after combining "artificial intelligence" and "deep learning" with "pandemic" to filter relevant articles published in 2000-2020. Additionally, considerable and appropriate AI writing appears in popular journals due to some of the AI information's proprietary and policy-related nature. Similar keywords were used in the Google ${ }^{\mathrm{TM}}$ search engine. Identified hits were reviewed by one of the authors in terms of relevance to this manuscript. Two other authors verified the information by cross-referencing the findings and searching PubMed with the peer-reviewed manuscripts most relevant to the investigated popular article. The authors believed that combining non-scientific and scientific sources produced a useful breadth of quality references on this topic that is more helpful for this audience than a limited search across peer-reviewed articles. The authors compared non-scientific sources wherever possible with scientific ones as described to achieve satisfactory validation. When independent publications covering similar subjects had no relevant peer-reviewed professional counterpart, the authors looked for the most representative article among the independent publications covering similar topics. 


\section{Results}

\subsection{How Can AI Be Used to Identify Emerging Biological Threats during Investigation and Detection?}

Severe acute respiratory syndrome (SARS), influenza virus H1N1, Middle Eastern respiratory virus (MERS), Zika virus, and Ebola have challenged world health in the 21st century to date [1,5-7]. The clinical presentations of new illnesses frequently make it difficult to distinguish them from known conditions, even when the potential for transmission is identified [15-19]. Interestingly, the review of the scientific literature revealed little peer-reviewed literature detailing the role of AI in the detection of pandemic emergence $[13,17,18,20,21]$. However, several technologies emerged, but they were used by private companies [17-19,22]. BlueDot, the company inspired by the SARS outbreak, used AI analysis of multiple data points and detected the outbreak in the middle of December 2019 [22]. In this case, analysis of news reports and postings on social media revealed an increase in the use of surgical masks coupled with the emergence of mysterious pneumonia, as did HealthMap [22,23]. Additional confirmation came from Dataminr, another AI company, which combined AI with humans on the ground observation [24]. These examples demonstrate the strength of AI-to sort through an enormous set of data for the clues escaping human analysis [10,25-27]. The same examples illustrate the importance of verifying the findings in the process of utilizing the AI [22,24,25]. These particular examples demonstrate that AI and humans augment each other, not being replacements.

The AI relies on a large amount of existing data to train pattern recognition, potentially suggesting that looking for a novel pandemic may not be the best application for AI [10,28]. However, AI can be pre-trained on similar diseases, e.g., by using MERS or SARS data for COVID-19 [9,10,23]. Furthermore, an alternative approach, zero-shot learning, seems to be particularly suitable in pandemic detection training for AI as it allows for learning when almost no clue is possible, but assumptions behind this technique (e.g., variables are independent) may be unrealistic [20,29]. The effectiveness of AI algorithms is challenging to study. The AI algorithms operated by Dataminr or BlueDot are not publicly available and, most likely, not comparable [30]. Other systems are more open in terms of public knowledge of their architecture. The study from 2012 demonstrated no difference in predictive values, yet, the manuscript is relatively old [17]. Lack of insight into how these systems are engineered, or perception of AI being a black box, may be one reason for poor reliance on AI-delivered warnings [9,11]. The industry approach to keep the algorithms hidden under the patent law is not helpful [30,31].

The early detection and forecast of new pandemic emergence provide a time to ramp up supplies, preparedness, and crash research programs. Unfortunately, human decision-makers failed to act according to the AI alert and prior virologists' warnings $[15,16,24]$. In other words, AI is but a tool in human hands $[10,28,32]$. Ignoring the warning from the best tool will render it useless. In stark contrast to ongoing mistrust in AI capabilities, Canada has moved into the "preparation stage" for the next pandemic and signed a contract with Bluedot for an early warning system to run continuously [22,33].

\subsection{Can AI Forecast and Mitigate the Spread of Biological Diseases during the Initiation and Acceleration of a Pandemic?}

Mitigation of a pandemic depends on the ability to identify infected individuals and actual and potential hotspots. BlueDot analyzed the tickets and flights from Wuhan and determined potential hotspots with very high accuracy in December [22]. Soon, other AI engines were forecasting the dynamics of outbreaks in Saudi Arabia, Egypt, Brazil, Canada, India, USA, and African countries [26,33-36]. The most popular approach in AI design incorporates a long-term short memory-based AI engine utilizing rolling training sets [26,33,37-39]. Others used advanced autoregressive integrated moving average $[18,35,40]$. It remains to be seen which of these AI engines perform with higher sensitivity. The data sources could be numerous and include governmental data, social media, and collateral data from mobile devices or public surveillance systems [17,37,38,41]. The relative scarcity of data for training constrains but does not prohibit AI development and deployment even when resources are limited [42]. Furthermore, the pre-training of AI can help counteract the fact that data are only limited. For example, 
BlueDot leveraged SARS data [22]. AI can couple existing large databases of living area characteristics (e.g., type of housing, population, and movement of people) with dynamics of the outbreak. Subsequently, AI provides even more accurate prediction of the disease spread, privacy concerns about collecting and sharing this data notwithstanding [22,24,25,42]. AI's potential to analyze at the level of a city, district, and neighborhood is a powerful feature of this technology $[10,25]$. The incorporation of contact tracing further augments the power of AI prediction in the spread of a pandemic [23]. The effect of mitigating measures can be studied to identify the most effective ones [43-45]. However, the accuracy of AI predictions varies in part with how well its pre-training aligns with actual events [38,46]. Of course, inappropriate predictions may lead to inaccurate estimation of the resources leading to misallocation of resources and inhibit pandemic mitigation $[38,46]$. Developing AI's predictive and analytical upside will, in turn, provide a robust base for overcoming arguably the most significant barrier to the use of AI, namely, the trust of humans and their political and social representatives.

\subsection{How Might AI Guide Medical Management and Resource Allocation during Acceleration and Deceleration of a Pandemic?}

Insufficient COVID-19 testing has significantly hampered diagnosing affected individuals. Radiologic alternatives to serology and viral tests were proposed to link emerging clinical symptoms to the COVID-19 infection. Some data suggest that radiological pieces of evidence are more robust [47-49]. Consequently, the Italian Society of Medical and Interventional Radiology suggested the use of AI to estimate prognosis for hospitalized patients, albeit stopping short of recommending the use of AI-analyzed CT images as a screening test [50]. Upside notwithstanding, neither the CDC nor the American College of Radiology (ACR) mentioned AI-guided image analysis and its potential to discern image features beyond traditional human-guided analysis [51]. Several other models for AI-augmented analysis of portable X-rays were proposed due to the higher accessibility of X-ray machines vs. CT scanners [52-54]. For several years, AI has been applied to image analysis, but even more significant progress was made when large, publicly available data were made available to the scientific community [12]. COVID-Net is an AI-based algorithm trained on the COVIDx database of over 13,000 images [55]. Authors had previously trained AI on pre-existing data sets before acquiring a specific COVID-19 data set, which enabled them to demonstrate AI's capacity to diagnose COVID-19 by image analysis [50,56-59]. The sheer size of the data is notable, but researchers' efforts to provide open, transparent, and validated tools for physicians are trailblazing and remarkable. Often, AI designers do not stress these features, which leads to limited reach and low trust in AI-driven protocols [60,61]. This may be of particular concern if non-radiological data such as chatbots, phone information, and web informatics are used to train $\mathrm{AI}[62,63]$.

AI-driven triage is a somewhat controversial application of this technology. However, the mismatch between the ability of a healthcare provider system to deliver health services and demands generated by patient influx is one of the top determinants of mortality in COVID-19. Hospitalized patients, and especially intensive care unit patients, necessitate very resource-intensive treatment for a prolonged period. When the healthcare system reaches saturation, healthcare providers have to make fast decisions regarding which incoming patients will receive care [64-67]. The COVID-19 pandemic precipitated several approaches to handling the mismatch, one being a framework based on a scoring system with modification for specific consideration, an example being the Italian College of Anesthesia, Resuscitation, and Intensive Care (SIAARTI) guidelines for the criteria that doctors should follow under COVID-19 [67]. This system follows the logic of several similar efforts outside pandemic situations. The United Network for Organ Sharing point systems provides an additional example of using quality-adjusted life-years and disability-adjusted life-years [68,69]. Others have advocated military-type triage based on age [70]. Using an AI-augmented triage protocol could also reduce the enormous stress related to making choices, which are repetitive and deeply challenging healthcare workers during the pandemic with significant ramifications during the pandemic and post-pandemic. Even slightly aiding a provider in deciding about resource allocation might well result in fewer and less intense cases of posttraumatic 
stress disorder (PTSD) among care providers, especially physicians [71,72]. Less extreme situations in emergency physicians and trauma surgeons result in PTSD [73,74]. Numerous predictive models of COVID-19 prognosis in various individuals based on AI-driven algorithms have been designed and published [75-80]. Their ability to distinguish between favorable outcomes and demise is significantly accurate. A few of them were implemented to test their suggestions in real life, a fact that leaves unaddressed concerns about dataset impartiality and concomitant ethical concerns about the implication of AI-driven decisions $[68,81,82]$. Both concerns can be addressed $[61,83]$. Firstly, allocating medical care in the absence of the best possible medical information hardly qualifies as the most ethical approach, unless one wishes to argue that willful ignorance qualifies as an ethical (or legal) defense. Second, AI can incorporate ethical standards into its algorithms $[31,64,66]$. Of course, incorporation does not guarantee that everyone will view the recommended decision as the most ethical possible.

A pandemic such as the COVID-19 one necessitates matching the illness to the level of care in large numbers of patients and the capacity to respond swiftly should their condition deteriorate $[3,4]$. Current healthcare systems often experience difficulty in detecting rapid changes in health conditions and struggle to adjust care accordingly. In the case of the COVID-19 pandemic, the presenting situation has been growing more complex as the healthcare system has been adding several remote, non-traditional locations, often employing biosensors, apps, or telemedicine [14,82,84]. Supervising care required by such a dynamic disease across heterogeneous care environments placed on care providers additional and complex demands. In other words, a physician need not, for example, rely solely on patient age, but on a rapidly evolving, data-driven prediction of the usefulness of resources in the successful treatment of any given patient $[14,65,85]$. In telemedicine, AI-driven algorithms have been introduced to score patient severity [86]. These protocols are relatively mature and augment physician decisions' quality by accounting for multiple factors not readily available to a caregiver. In the specific case of the current pandemic, Stanford University and the University of Colorado adopted systems for COVID-19 patients trying to predict which patients would deteriorate [87]. The operationalization of these AI-driven algorithms in some critical care situations has demonstrated their effectiveness, but regulatory agencies need to discover a fast-track system for their approval [11]. In a protracted pandemic, AI provides the unrealized potential to allow a healthcare system to adapt more quickly to illness severity, patient by patient, while better protecting its workforce's mental and emotional well-being.

Patient with COVID-19 are very resource-consuming [1,88]. They require sedation, supportive medication, nutrition, care, and ongoing attention while on supportive respiratory care [4]. The associated demand for medications, durable supplies, expendable items, space, and various types of personnel can produce costly and dangerous bottlenecks [89]. This demand pushes the limits of the existing equipment, including PPE. To date, the response has appeared decentralized and uncoordinated, with locales and nations competing for the same limited resources [89]. Govindan et al. suggest using a decision support system with several factors to guide healthcare resource allocation. The next step is the use of AI to analyze the data $[14,85]$. AI can couple outbreak data with measures of potential demand and direct the supplies more efficiently by directing resources into anticipated hotspots before full-blown local or national crises emerge as well as adjust for individual care [90,91].

Better predictions about a pandemic's course enable more effective deployment of healthcare and societal resources [64,92]. Assessment of the likelihood of patient's survival during initial triage and hospitalization may augment the allocation of healthcare assets on the level of a ward, hospital, or larger geographical area. Triage and outcome prediction are very controversial areas of AI application with the medical community and public unprepared for these applications [77,93]. AI can improve resource allocation and help assess the countries' preparedness by taking into account the dynamic of the spread and available resources, factors frequently minimized in classic epidemiological models [94]. 


\subsection{How Might AI Accelerate the Development of Medical Therapies and Treatment Protocols?}

The COVID-19 pandemic has resulted in at least three significant types of AI contributions in the development of science-based treatment of COVID-19.

First, machine learning has helped scientists search through the overwhelming amount of research produced about COVID-19 to inform treatment. For example, the Allen Institute for AI, partnering with several research organizations, created the "COVID-19 Open Research Dataset" (CORD-19) which contains over 44,000 scholarly articles about COVID-19 and SARS-CoV-2, updated daily and machine-readable [95]. A similarly curated dataset, LitCOVID, is available via the NIH, but it is manually curated [96].

Secondly, AI played a significant, if largely unrecognized, role in drug development during SARS by suggesting therapeutic compounds even before the emergence of COVID-19 [21,97]. Regarding COVID-19, it can deliver compound selection clues superior to the initial recommendations of Plaquenil or azithromycin to treat COVID-19, i.e., the recommendations based on underpowered, anecdotal, and methodologically troublesome studies [88]. Early on, an AI application identified 78 novel small molecules as candidates to test for rapid testing as potential treatment compounds. A European group screened the existing compounds suggesting possible treatments [98-100]. In this manner, AI offers researchers a novel tool to accelerate selection of the existing medications and the development of original molecules. Such identification does not replace the need for clinical trials, but it can focus clinical trials on the most promising therapeutic compounds.

Furthermore, AI may aid in repurposing existing medications for COVID-19 treatment and thus leverage the advantages of the existing approval use: fewer regulatory hurdles and rapid trial cycle [98]. BenevolentAI, one of several groups leveraging AI, engaged in precisely this kind of targeted discovery and trial process, identified baricitinib as a leading candidate for COVID-19 treatment [101]. This compound underwent a promising if limited clinical trial in Italy and has now entered US clinical trials with Eli Lilly and the National Institute of Allergy and Infectious Diseases.

Thirdly, AI can aid rapid acceleration of the development of an effective vaccine. In the US, the Vaccine Research Institute began turning away from traditional vaccine development in 2018, employing instead newer technologies using either DNA or messenger RNA that could potentially work for multiple viruses [102]. Academic institutions followed suit in the wake of COVID-19. Having these platforms available offers the possibility of shortening the development of a vaccine from 20 months to just over 3 months. Moderna had developed eight mRNA vaccines for a variety of viruses and used AI to choose the most promising therapeutic options in the fight against COVID-19 [102,103].

In short, AI can delve deeply and broadly into what humans know in the service of focusing attention on where to delve more deeply and, as importantly, where not to waste valuable time [104,105] on care protocols or potential compounds and vaccines.

\subsection{Weaknesses of $A I$}

AI carries the possibility of refined impartiality, a key contributor to its potential acceptance. However, "garbage in / garbage out" highlights the real possibility of embedding human errors and biases in AI For example, the Correctional Offender Management Profiling for Alternative Sanctions (COMPAS) system, an algorithm designed to aid the judicial system, replicated common biases and errors [106]. Only the most careful attention will allow us to make those errors and biases visible so that they can be recognized and addressed [107,108].

Healthcare providers are underrepresented in AI development despite considerable expressed interest [10]. Such underrepresentation will likely lead to several weaknesses: more reluctant acceptance thereof by caregivers, particularly by physicians, and less infusion of traditional medical values into its development [109]. Unfortunately, physicians have limited opportunities during their education to familiarize themselves with $\mathrm{AI}$ and the related concepts. Healthcare providers need far more education in AI development and use to understand and facilitate its development and application. 


\section{Final Points}

The strength of artificial intelligence comes down to its ability to synthesize a vast amount of data quickly and in a way that humans simply cannot. In a pandemic, data emerge rapidly, proving too voluminous, too varied, and too fast-changing for humans to process into information as quickly as AI can (Table 1). It can more quickly determine which variables determine recovery and which appear irrelevant for a specific patient [10]. Additionally, AI can sort through the effects of practice biases such as the amount of ventilation pressure employed, a practice that varies by country, and so decrease the variation in the decisions made by individual healthcare providers [10]. In short, AI offers the potential to support faster development of clinical protocols for a new and evolving disease such as COVID-19.

Table 1. The promise and peril of using AI in pandemics.

\begin{tabular}{|c|c|c|c|c|c|}
\hline Key Questions & & The Promise of AI & & The Peril of AI & References \\
\hline $\begin{array}{l}\text { How can AI be used to } \\
\text { identify emerging } \\
\text { biological threats? }\end{array}$ & $\bigcirc$ & $\begin{array}{l}\text { Early detection of the } \\
\text { leading indicators }\end{array}$ & $\bigcirc$ & $\begin{array}{l}\text { Need for prompt human } \\
\text { validation and response }\end{array}$ & {$[1,9-12,15,17,26,63-67]$} \\
\hline $\begin{array}{c}\text { Can AI mitigate the } \\
\text { spread of biological } \\
\text { diseases and guide early } \\
\text { treatment? }\end{array}$ & 0 & $\begin{array}{l}\text { Contact tracing and aggregation } \\
\text { feeding prediction of } \\
\text { contagion spread } \\
\text { Rapid evaluation of treatment } \\
\text { options based on prior } \\
\text { similar events }\end{array}$ & $\bigcirc$ & $\begin{array}{l}\text { Privacy and } \\
\text { appropriateness of } \\
\text { predictive modeling }\end{array}$ & {$[1,11,12,68]$} \\
\hline $\begin{array}{l}\text { How might AI guide } \\
\text { medical management } \\
\text { and resource allocation? }\end{array}$ & $\begin{array}{l}0 \\
0\end{array}$ & $\begin{array}{l}\text { Image analysis-driven diagnosis } \\
\text { of disease existence, severity, } \\
\text { and prognosis } \\
\text { Resource allocation informed by } \\
\text { ongoing data-based } \\
\text { determination of the likely } \\
\text { medical outcome } \\
\text { Reduce stress on } \\
\text { medical personnel } \\
\text { Sophisticated and developing } \\
\text { analysis of optimum resource } \\
\text { allocation across any chosen } \\
\text { variable set (e.g., likely outcome, } \\
\text { current and likely resource } \\
\text { availability, and probable } \\
\text { near-term demand) }\end{array}$ & 0 & $\begin{array}{l}\text { Refined analysis of poorly } \\
\text { refined, incomplete, } \\
\text { or biased data } \\
\text { Abdication of human } \\
\text { responsibility for } \\
\text { triage decision-making }\end{array}$ & {$[13-18,20,25,26,37,69-72]$} \\
\hline $\begin{array}{c}\text { How might AI accelerate } \\
\text { development of medical } \\
\text { therapies and treatment } \\
\text { protocols? }\end{array}$ & 0 & $\begin{array}{l}\text { Rapid identification of treatment } \\
\text { and vaccine candidates }\end{array}$ & O & $\begin{array}{l}\text { Erroneous delegation of } \\
\text { decisions to AI with } \\
\text { insufficient human } \\
\text { oversight, e.g., of clinical } \\
\text { trials or the role of } \\
\text { social disparities }\end{array}$ & {$[41-43,45,46,48,73]$} \\
\hline
\end{tabular}

Not surprisingly, the notion of incorporating AI decision-making in healthcare stirs considerable controversy, including about responsibility and ethics [13,32]. However, the point here is not that AI will make more and better decisions, but rather that it could facilitate more targeted and ethical decision-making. AI will provide a consistency of application and can, under human supervision, serve to broaden and explicate ethical considerations before disasters such as pandemics strike and necessitate all too profound choices. People could take any of a number of approaches to creating standards to govern development and supervision of AI, be it for healthcare or for autonomous vehicles [31,68,69,110]. 
In closing, the authors highlight three sets of questions worthy of careful exploration. First, who is responsible for AI in healthcare? The hospital system? The creators of any given AI application? If AI achieves the level of self-programming, who carries responsibility for its actions from then onward? Second, who should own AI? Currently, many private entities conduct much of AI development [30]. Does the fact that AI in healthcare will likely include triage and other life and death decisions argue sufficiently for more universal ownership or at least governance? Does the power of AI argue for a definition of "universal" as nothing less than global? Third, if AI can become independent and self-developing, then should it?

Author Contributions: K.L.-concept, literature search, initial writing, submission; G.S.—concept, development of the manuscript; M.D.-concept, development of the manuscript; C.S. concept, literature search, development of the manuscript; M.R.- - development of the manuscript, initial writing, submission. All authors have read and agreed to the published version of the manuscript.

Funding: This research received no external funding.

Conflicts of Interest: The authors declare no conflict of interest.

\section{References}

1. Bogoch, I.I.; Watts, A.; Thomas-Bachli, A.; Huber, C.; Kraemer, M.U.G.; Khan, K. Pneumonia of unknown aetiology in Wuhan, China: Potential for international spread via commercial air travel. J. Travel Med. 2020, 27, taaa008. [CrossRef]

2. Contini, C.; Di Nuzzo, M.; Barp, N.; Bonazza, A.; De Giorgio, R.; Tognon, M.; Rubino, S. The novel zoonotic COVID-19 pandemic: An expected global health concern. J. Infect. Dev. Ctries. 2020, 14, 254-264. [CrossRef]

3. Nicola, M.; O'Neill, N.; Sohrabi, C.; Khan, M.; Agha, M.; Agha, R. Evidence based management guideline for the COVID-19 pandemic-Review article. Int. J. Surg. 2020, 77, 206-216. [CrossRef] [PubMed]

4. Poston, J.T.; Patel, B.K.; Davis, A.M. Management of Critically Ill Adults with COVID-19. JAMA 2020, 323, 1839-1841. [CrossRef] [PubMed]

5. Chen, Z.L.; Zhang, W.J.; Lu, Y.; Guo, C.; Guo, Z.M.; Liao, C.H.; Zhang, X.; Zhang, Y.; Han, X.H.; Li, Q.L.; et al. From severe acute respiratory syndrome-associated coronavirus to 2019 novel coronavirus outbreak: Similarities in the early epidemics and prediction of future trends. Chin. Med. J. 2020, 133, 1112-1114. [CrossRef] [PubMed]

6. Dawood, F.S.; Jain, S.; Finelli, L.; Shaw, M.W.; Lindstrom, S.; Garten, R.J.; Gubareva, L.V.; Xu, X.; Bridges, C.B.; Uyeki, T.M. Emergence of a novel swine-origin influenza A (H1N1) virus in humans. N. Engl. J. Med. 2009, 360, 2605-2615. [CrossRef] [PubMed]

7. Schuler-Faccini, L.; Ribeiro, E.M.; Feitosa, I.M.; Horovitz, D.D.; Cavalcanti, D.P.; Pessoa, A.; Doriqui, M.J.; Neri, J.I.; Neto, J.M.; Wanderley, H.Y.; et al. Possible Association between Zika Virus Infection and Microcephaly-Brazil, 2015. MMWR Morb. Mortal. Wkly. Rep. 2016, 65, 59-62. [CrossRef]

8. Holloway, R.; Rasmussen, S.A.; Zaza, S.; Cox, N.J.; Jernigan, D.B. Updated preparedness and response framework for influenza pandemics. MMWR Recomm. Rep. 2014, 63, 1-18.

9. Ahmed, Z.; Mohamed, K.; Zeeshan, S.; Dong, X. Artificial intelligence with multi-functional machine learning platform development for better healthcare and precision medicine. Database J. Biol. Databases Curation 2020, 2020, baaa010. [CrossRef]

10. Davenport, T.; Kalakota, R. The potential for artificial intelligence in healthcare. Future Healthc. J. 2019, 6, 94-98. [CrossRef]

11. Gutierrez, G. Artificial Intelligence in the Intensive Care Unit. Crit. Care 2020, 24, 101. [CrossRef] [PubMed]

12. Hosny, A.; Parmar, C.; Quackenbush, J.; Schwartz, L.H.; Aerts, H. Artificial intelligence in radiology. Nat. Rev. Cancer 2018, 18, 500-510. [CrossRef] [PubMed]

13. Niel, O.; Bastard, P. Artificial Intelligence in Nephrology: Core Concepts, Clinical Applications, and Perspectives. Am. J. Kidney Dis. 2019, 74, 803-810. [CrossRef] [PubMed]

14. Ting, D.S.W.; Carin, L.; Dzau, V.; Wong, T.Y. Digital technology and COVID-19. Nat. Med. 2020, $26,459-461$. [CrossRef] [PubMed] 
15. Ksiazek, T.G.; Erdman, D.; Goldsmith, C.S.; Zaki, S.R.; Peret, T.; Emery, S.; Tong, S.; Urbani, C.; Comer, J.A.; Lim, W.; et al. A novel coronavirus associated with severe acute respiratory syndrome. N. Engl. J. Med. 2003, 348, 1953-1966. [CrossRef] [PubMed]

16. Poon, L.L. SARS and other coronaviruses in humans and animals. Adv. Exp. Med. Biol. 2006, 581, 457-462. [CrossRef] [PubMed]

17. Lyon, A.; Nunn, M.; Grossel, G.; Burgman, M. Comparison of web-based biosecurity intelligence systems: BioCaster, EpiSPIDER and HealthMap. Transbound. Emerg. Dis. 2012, 59, 223-232. [CrossRef] [PubMed]

18. Freifeld, C.C.; Mandl, K.D.; Reis, B.Y.; Brownstein, J.S. HealthMap: Global infectious disease monitoring through automated classification and visualization of Internet media reports. J. Am. Med. Inform. Assoc. 2008, 15, 150-157. [CrossRef] [PubMed]

19. Hossain, N.; Househ, M. Using HealthMap to Analyse Middle East Respiratory Syndrome (MERS) Data. Stud. Health Technol. Inform. 2016, 226, 213-216. [PubMed]

20. Rezaei, M.; Shahidi, M. Zero-Shot Learning and its Applications from Autonomous Vehicles to COVID-19 Diagnosis: A Review. Intell. Based Med. 2020, 3-4, 100005. [CrossRef] [PubMed]

21. De Wilde, A.H.; Jochmans, D.; Posthuma, C.C.; Zevenhoven-Dobbe, J.C.; van Nieuwkoop, S.; Bestebroer, T.M.; van den Hoogen, B.G.; Neyts, J.; Snijder, E.J. Screening of an FDA-approved compound library identifies four small-molecule inhibitors of Middle East respiratory syndrome coronavirus replication in cell culture. Antimicrob. Agents Chemother. 2014, 58, 4875-4884. [CrossRef] [PubMed]

22. BlueDot Protects People around the World from Infectious Diseases with Human and Artificial Intelligence. 2020. Available online: https://bluedot.global/about/ (accessed on 15 May 2020).

23. Agbehadji, I.E.; Awuzie, B.O.; Ngowi, A.B.; Millham, R.C. Review of Big Data Analytics, Artificial Intelligence and Nature-Inspired Computing Models towards Accurate Detection of COVID-19 Pandemic Cases and Contact Tracing. Int. J. Environ. Res. Public Health 2020, 17, 5330. [CrossRef] [PubMed]

24. Dataminr. Real-Time Event and Risk Detection. 2020. Available online: https://www.dataminr.com (accessed on 15 May 2020).

25. An AI Epidemiologist Sent the First Warnings of the Wuhan Virus. Available online: https://utulsa.edu/an-ai -epidemiologist-sent-the-first-warnings-of-the-wuhan-virus/ (accessed on 15 May 2020).

26. Wang, P.; Zheng, X.; Ai, G.; Liu, D.; Zhu, B. Time series prediction for the epidemic trends of COVID-19 using the improved LSTM deep learning method: Case studies in Russia, Peru and Iran. Chaos Solitons Fractals 2020, 140, 110214. [CrossRef]

27. Kim, Y.J.; Kelley, B.P.; Nasser, J.S.; Chung, K.C. Implementing Precision Medicine and Artificial Intelligence in Plastic Surgery: Concepts and Future Prospects. Plast. Reconstr. Surg. Glob. Open 2019, 7, e2113. [CrossRef] [PubMed]

28. Matheny, M.E.; Whicher, D.; Thadaney Israni, S. Artificial Intelligence in Health Care: A Report from the National Academy of Medicine. JAMA 2020, 323, 509-510. [CrossRef] [PubMed]

29. Xu, X.; Tsang, I.W.; Liu, C. Complementary Attributes: A New Clue to Zero-Shot Learning. IEEE Trans. Cybern. 2019. [CrossRef] [PubMed]

30. Benkler, Y. Don't let industry write the rules for AI. Nature 2019, 569, 161. [CrossRef] [PubMed]

31. O'Sullivan, S.; Nevejans, N.; Allen, C.; Blyth, A.; Leonard, S.; Pagallo, U.; Holzinger, K.; Holzinger, A.; Sajid, M.I.; Ashrafian, H. Legal, regulatory, and ethical frameworks for development of standards in artificial intelligence (AI) and autonomous robotic surgery. Int. J. Med. Robot. Comput. Assist. Surg. MRCAS 2019, 15, e1968. [CrossRef]

32. Kluge, E.W. Artificial intelligence in healthcare: Ethical considerations. Healthc. Manag. Forum 2020, 33, 47-49. [CrossRef]

33. Chimmula, V.K.R.; Zhang, L. Time series forecasting of COVID-19 transmission in Canada using LSTM networks. Chaos Solitons Fractals 2020, 135, 109864. [CrossRef]

34. Elsheikh, A.H.; Saba, A.I.; Elaziz, M.A.; Lu, S.; Shanmugan, S.; Muthuramalingam, T.; Kumar, R.; Mosleh, A.O.; Essa, F.A.; Shehabeldeen, T.A. Deep learning-based forecasting model for COVID-19 outbreak in Saudi Arabia. Process Saf. Environ. Prot. Trans. Inst. Chem. Eng. Part B 2020, 149, 223-233. [CrossRef] [PubMed]

35. Saba, A.I.; Elsheikh, A.H. Forecasting the prevalence of COVID-19 outbreak in Egypt using nonlinear autoregressive artificial neural networks. Process Saf. Environ. Prot. Trans. Inst. Chem. Eng. Part B 2020, 141, 1-8. [CrossRef] [PubMed] 
36. Hawas, M. Generated time-series prediction data of COVID-19's daily infections in Brazil by using recurrent neural networks. Data Brief 2020, 32, 106175. [CrossRef] [PubMed]

37. Jung, S.Y.; Jo, H.; Son, H.; Hwang, H.J. Real-World Implications of a Rapidly Responsive COVID-19 Spread Model with Time-Dependent Parameters via Deep Learning: Model Development and Validation. J. Med. Internet Res. 2020, 22, e19907. [CrossRef]

38. Prasanth, S.; Singh, U.; Kumar, A.; Tikkiwal, V.A.; Chong, P.H.J. Forecasting spread of COVID-19 using Google Trends: A hybrid GWO-Deep learning approach. Chaos Solitons Fractals 2020, 110336. [CrossRef]

39. Shastri, S.; Singh, K.; Kumar, S.; Kour, P.; Mansotra, V. Time series forecasting of Covid-19 using deep learning models: India-USA comparative case study. Chaos Solitons Fractals 2020, 140, 110227. [CrossRef] [PubMed]

40. Pourghasemi, H.R.; Pouyan, S.; Farajzadeh, Z.; Sadhasivam, N.; Heidari, B.; Babaei, S.; Tiefenbacher, J.P. Assessment of the outbreak risk, mapping and infection behavior of COVID-19: Application of the autoregressive integrated-moving average (ARIMA) and polynomial models. PLoS ONE 2020, 15, e0236238. [CrossRef] [PubMed]

41. Park, H.W.; Park, S.; Chong, M. Conversations and Medical News Frames on Twitter: Infodemiological Study on COVID-19 in South Korea. J. Med. Internet Res. 2020, 22, e18897. [CrossRef] [PubMed]

42. Evans, M.V.; Garchitorena, A.; Rakotonanahary, R.J.L.; Drake, J.M.; Andriamihaja, B.; Rajaonarifara, E.; Ngonghala, C.N.; Roche, B.; Bonds, M.H.; Rakotonirina, J. Reconciling model predictions with low reported cases of COVID-19 in Sub-Saharan Africa: Insights from Madagascar. Glob. Health Action 2020, 13, 1816044. [CrossRef] [PubMed]

43. Srivastava, V.; Srivastava, S.; Chaudhary, G.; Al-Turjman, F. A systematic approach for COVID-19 predictions and parameter estimation. Pers. Ubiquitous Comput. 2020, 1-13. [CrossRef]

44. Ansumali, S.; Kaushal, S.; Kumar, A.; Prakash, M.K.; Vidyasagar, M. Modelling a pandemic with asymptomatic patients, impact of lockdown and herd immunity, with applications to SARS-CoV-2. Annu. Rev. Control 2020. [CrossRef] [PubMed]

45. Paital, B.; Das, K.; Parida, S.K. Inter nation social lockdown versus medical care against COVID-19, a mild environmental insight with special reference to India. Sci. Total Environ. 2020, 728, 138914. [CrossRef] [PubMed]

46. Singh, S.; Murali Sundram, B.; Rajendran, K.; Boon Law, K.; Aris, T.; Ibrahim, H.; Chandra Dass, S.; Singh Gill, B. Forecasting daily confirmed COVID-19 cases in Malaysia using ARIMA models. J. Infect. Dev. Ctri. 2020, 14, 971-976. [CrossRef] [PubMed]

47. He, J.L.; Luo, L.; Luo, Z.D.; Lyu, J.X.; Ng, M.Y.; Shen, X.P.; Wen, Z. Diagnostic performance between CT and initial real-time RT-PCR for clinically suspected 2019 coronavirus disease (COVID-19) patients outside Wuhan, China. Respir. Med. 2020, 168, 105980. [CrossRef] [PubMed]

48. Lessmann, N.; Sánchez, C.I.; Beenen, L.; Boulogne, L.H.; Brink, M.; Calli, E.; Charbonnier, J.P.; Dofferhoff, T.; van Everdingen, W.M.; Gerke, P.K.; et al. Automated Assessment of CO-RADS and Chest CT Severity Scores in Patients with Suspected COVID-19 Using Artificial Intelligence. Radiology 2020, 202439. [CrossRef]

49. Li, Z.; Zhong, Z.; Li, Y.; Zhang, T.; Gao, L.; Jin, D.; Sun, Y.; Ye, X.; Yu, L.; Hu, Z.; et al. From community-acquired pneumonia to COVID-19: A deep learning-based method for quantitative analysis of COVID-19 on thick-section CT scans. Eur. Radiol. 2020, 30, 6828-6837. [CrossRef]

50. Neri, E.; Miele, V.; Coppola, F.; Grassi, R. Use of CT and artificial intelligence in suspected or COVID-19 positive patients: Statement of the Italian Society of Medical and Interventional Radiology. Radiol. Med. 2020, 125, 505-508. [CrossRef]

51. ACR Issues Statement for Use of Chest Radiography, CT for Suspected COVID-19 Infection. 2020. Available online: https://appliedradiology.com/communities/CT-Imaging/acr-issues-statement-for-use-of-chest-ra diography-ct-for-suspected-covid-19-infection (accessed on 15 May 2020).

52. Rahimzadeh, M.; Attar, A. A modified deep convolutional neural network for detecting COVID-19 and pneumonia from chest X-ray images based on the concatenation of Xception and ResNet50V2. Inform. Med. Unlocked 2020, 19, 100360. [CrossRef]

53. Chowdhury, N.K.; Rahman, M.M.; Kabir, M.A. PDCOVIDNet: A parallel-dilated convolutional neural network architecture for detecting COVID-19 from chest X-ray images. Health Inf. Sci. Syst. 2020, 8, 27. [CrossRef] 
54. Lee, K.S.; Kim, J.Y.; Jeon, E.T.; Choi, W.S.; Kim, N.H.; Lee, K.Y. Evaluation of Scalability and Degree of Fine-Tuning of Deep Convolutional Neural Networks for COVID-19 Screening on Chest X-ray Images Using Explainable Deep-Learning Algorithm. J. Pers. Med. 2020, 10, 213. [CrossRef]

55. Wang, L.; Lin, Z.Q.; Wong, A. COVID-Net: A tailored deep convolutional neural network design for detection of COVID-19 cases from chest X-ray images. Sci. Rep. 2020, 10, 19549. [CrossRef] [PubMed]

56. Li, D.; Wang, D.; Dong, J.; Wang, N.; Huang, H.; Xu, H.; Xia, C. False-Negative Results of Real-Time Reverse-Transcriptase Polymerase Chain Reaction for Severe Acute Respiratory Syndrome Coronavirus 2: Role of Deep-Learning-Based CT Diagnosis and Insights from Two Cases. Korean J. Radiol. 2020, 21, 505-508. [CrossRef] [PubMed]

57. Ai, T.; Yang, Z.; Hou, H.; Zhan, C.; Chen, C.; Lv, W.; Tao, Q.; Sun, Z.; Xia, L. Correlation of Chest CT and RT-PCR Testing in Coronavirus Disease 2019 (COVID-19) in China: A Report of 1014 Cases. Radiology 2020, 200642. [CrossRef] [PubMed]

58. Schwyzer, M.; Martini, K.; Skawran, S.; Messerli, M.; Frauenfelder, T. Pneumonia Detection in Chest X-Ray Dose-Equivalent CT: Impact of Dose Reduction on Detectability by Artificial Intelligence. Acad. Radiol. 2020. [CrossRef] [PubMed]

59. Belfiore, M.P.; Urraro, F.; Grassi, R.; Giacobbe, G.; Patelli, G.; Cappabianca, S.; Reginelli, A. Artificial intelligence to codify lung CT in Covid-19 patients. Radiol. Med. 2020, 125, 500-504. [CrossRef]

60. Cath, C. Governing artificial intelligence: Ethical, legal and technical opportunities and challenges. Philos. Trans. Math Phys. Eng. Sci. 2018, 376. [CrossRef]

61. Chen, M.; Decary, M. Artificial intelligence in healthcare: An essential guide for health leaders. Healthc. Manag. Forum 2020, 33, 10-18. [CrossRef]

62. Martin, A.; Nateqi, J.; Gruarin, S.; Munsch, N.; Abdarahmane, I.; Zobel, M.; Knapp, B. An artificial intelligence-based first-line defence against COVID-19: Digitally screening citizens for risks via a chatbot. Sci. Rep. 2020, 10, 19012. [CrossRef]

63. Badell-Grau, R.A.; Cuff, J.P.; Kelly, B.P.; Waller-Evans, H.; Lloyd-Evans, E. Investigating the Prevalence of Reactive Online Searching in the COVID-19 Pandemic: Infoveillance Study. J. Med. Internet Res. 2020, 22, e19791. [CrossRef]

64. Knebel, A.R.; Sharpe, V.A.; Danis, M.; Toomey, L.M.; Knickerbocker, D.K. Informing the gestalt: An ethical framework for allocating scarce federal public health and medical resources to states during disasters. Disaster Med. Public Health Prep. 2014, 8, 79-88. [CrossRef]

65. Wolf, L.; Hensel, W. Valuing lives: Allocating scarce medical resources during a public health emergency and the Americans with Disabilities Act (perspective). PLoS Curr. 2011, 3, RRN1271. [CrossRef] [PubMed]

66. Daugherty Biddison, E.L.; Gwon, H.; Schoch-Spana, M.; Cavalier, R.; White, D.B.; Dawson, T.; Terry, P.B.; London, A.J.; Regenberg, A.; Faden, R.; et al. The community speaks: Understanding ethical values in allocation of scarce lifesaving resources during disasters. Ann. Am. Thorac. Soc. 2014, 11, 777-783. [CrossRef] [PubMed]

67. Vergano, M.; Bertolini, G.; Giannini, A.; Gristina, G.R.; Livigni, S.; Mistraletti, G.; Riccioni, L.; Petrini, F. Clinical ethics recommendations for the allocation of intensive care treatments in exceptional, resource-limited circumstances: The Italian perspective during the COVID-19 epidemic. Crit. Care 2020, 24, 165. [CrossRef] [PubMed]

68. Cao, H.; Huang, S. Principles of scarce medical resource allocation in natural disaster relief: A simulation approach. Med. Decis. Mak. 2012, 32, 470-476. [CrossRef] [PubMed]

69. Persad, G.; Wertheimer, A.; Emanuel, E.J. Principles for allocation of scarce medical interventions. Lancet 2009, 373, 423-431. [CrossRef]

70. Huesch, M.D. One and done? Equality of opportunity and repeated access to scarce, indivisible medical resources. BMC Med. Ethics 2012, 13, 11. [CrossRef]

71. Guo, R.; Farnsworth, T.J.; Hermanson, P.M. Information Resources for Hospital Administrator Healthcare Management Decision-Making. J. Hosp. Librariansh. 2015, 15, 274-283. [CrossRef]

72. Lai, J.; Ma, S.; Wang, Y.; Cai, Z.; Hu, J.; Wei, N.; Wu, J.; Du, H.; Chen, T.; Li, R.; et al. Factors Associated With Mental Health Outcomes Among Health Care Workers Exposed to Coronavirus Disease 2019. JAMA Netw. Open 2020, 3, e203976. [CrossRef] 
73. Sherman, M.F.; Gershon, R.R.; Riley, H.E.M.; Zhi, Q.; Magda, L.A.; Peyrot, M. Emergency Preparedness Safety Climate and Other Factors Associated with Mental Health Outcomes among World Trade Center Disaster Evacuees. Disaster Med. Public Health Prep. 2017, 11, 326-336. [CrossRef]

74. DeLucia, J.A.; Bitter, C.; Fitzgerald, J.; Greenberg, M.; Dalwari, P.; Buchanan, P. Prevalence of Post-Traumatic Stress Disorder in Emergency Physicians in the United States. West. J. Emerg. Med. 2019, 20, 740-746. [CrossRef]

75. Di Castelnuovo, A.; Bonaccio, M.; Costanzo, S.; Gialluisi, A.; Antinori, A.; Berselli, N.; Blandi, L.; Bruno, R.; Cauda, R.; Guaraldi, G.; et al. Common cardiovascular risk factors and in-hospital mortality in 3894 patients with COVID-19: Survival analysis and machine learning-based findings from the multicentre Italian CORIST Study. Nutr. Metab. Cardiovasc. Dis. 2020, 30, 1899-1913. [CrossRef] [PubMed]

76. Hu, Z.J.; Xu, J.; Yin, J.M.; Li, L.; Hou, W.; Zhang, L.L.; Zhou, Z.; Yu, Y.Z.; Li, H.J.; Feng, Y.M.; et al. Lower Circulating Interferon-Gamma Is a Risk Factor for Lung Fibrosis in COVID-19 Patients. Front. Immunol. 2020, 11, 585647. [CrossRef] [PubMed]

77. Lai, L.; Wittbold, K.A.; Dadabhoy, F.Z.; Sato, R.; Landman, A.B.; Schwamm, L.H.; He, S.; Patel, R.; Wei, N.; Zuccotti, G.; et al. Digital triage: Novel strategies for population health management in response to the COVID-19 pandemic. Healthcare 2020, 8, 100493. [CrossRef] [PubMed]

78. Chassagnon, G.; Vakalopoulou, M.; Battistella, E.; Christodoulidis, S.; Hoang-Thi, T.N.; Dangeard, S.; Deutsch, E.; Andre, F.; Guillo, E.; Halm, N.; et al. AI-driven quantification, staging and outcome prediction of COVID-19 pneumonia. Med. Image Anal. 2020, 67, 101860. [CrossRef]

79. Suri, J.S.; Puvvula, A.; Biswas, M.; Majhail, M.; Saba, L.; Faa, G.; Singh, I.M.; Oberleitner, R.; Turk, M.; Chadha, P.S.; et al. COVID-19 pathways for brain and heart injury in comorbidity patients: A role of medical imaging and artificial intelligence-based COVID severity classification: A review. Comput. Biol. Med. 2020, 124, 103960. [CrossRef]

80. Gao, Y.; Cai, G.Y.; Fang, W.; Li, H.Y.; Wang, S.Y.; Chen, L.; Yu, Y.; Liu, D.; Xu, S.; Cui, P.F.; et al. Machine learning based early warning system enables accurate mortality risk prediction for COVID-19. Nat. Commun. 2020, 11, 5033. [CrossRef]

81. Neves, N.; Bitencourt, F.; Bitencourt, A.G.V. Ethical dilemmas in COVID-19 times: How to decide who lives and who dies? Rev. Assoc. Med. Bras. 2020, 66 (Suppl. S2), 106-111. [CrossRef]

82. Suh, S.; Lee, H.; Lukowicz, P.; Lee, Y.O. CEGAN: Classification Enhancement Generative Adversarial Networks for unraveling data imbalance problems. Neural Netw. Off. J. Int. Neural Netw. Soc. 2020, 133, 69-86. [CrossRef]

83. Blobel, B.; Ruotsalainen, P.; Brochhausen, M.; Oemig, F.; Uribe, G.A. Autonomous Systems and Artificial Intelligence in Healthcare Transformation to 5P Medicine-Ethical Challenges. Stud. Health Technol. Inform. 2020, 270, 1089-1093. [CrossRef]

84. Lian, W.; Wen, L.; Zhou, Q.; Zhu, W.; Duan, W.; Xiao, X.; Mhungu, F.; Huang, W.; Li, C.; Cheng, W.; et al. Emergency response to the COVID-19 pandemic using digital health technologies: Practical experience of a tertiary hospital in China. J. Med. Internet Res. 2020. [CrossRef]

85. Govindan, K.; Mina, H.; Alavi, B. A decision support system for demand management in healthcare supply chains considering the epidemic outbreak: A case study of coronavirus disease 2019 (COVID-19). Transp. Res. Part E Logist. Transp. Rev. 2020, 138, 101967. [CrossRef] [PubMed]

86. Jiang, X.; Coffee, M.; Bari, A.; Wang, J.; Jiang, X.; Huang, J.; Shi, J.; Dai, J.; Cai, J.; Zhang, T.; et al. Towards an artificial intelligence framework for data-driven prediction of coronavirus clinical severity. Comput. Mater. Contin. 2020, 63, 537-551. [CrossRef]

87. Doctors Are Using AI to Triage COVID-19 Patients. the Tools May Be Here to Stay. Available online: https: //axisimagingnews.com/imaging-news/doctors-are-using-ai-to-triage-covid-19-patients-the-tools-may-be -here-to-stay (accessed on 15 May 2020).

88. Baden, L.R.; Rubin, E.J. Covid-19-The Search for Effective Therapy. N. Engl. J. Med. 2020, 382, 1851-1852. [CrossRef] [PubMed]

89. Whalen, J.; Romm, T.; Gregg, A.; Hamburger, T. Scramble for Medical Equipment Descends into Chaos as U.S. States and Hospitals Compete for Rare Supplies. Available online: https://www.washingtonpost.com/business/ 2020/03/24/scramble-medical-equipment-descends-into-chaos-us-states-hospitals-compete-rare-supplies/ (accessed on 25 March 2020). 
90. Srinivasa Rao, A.S.R.; Vazquez, J.A. Identification of COVID-19 can be quicker through artificial intelligence framework using a mobile phone-based survey when cities and towns are under quarantine. Infect. Control Hosp. Epidemiol. 2020, 41, 826-830. [CrossRef] [PubMed]

91. Chakir, I.; El Khaili, M.; Mestari, M. Logistics Flow Optimization for Advanced Management of the Crisis Situation. Procedia Comput. Sci. 2020, 175, 419-426. [CrossRef] [PubMed]

92. Rasul, G. A Framework for Improving Policy Priorities in Managing COVID-19 Challenges in Developing Countries. Front. Public Health 2020, 8, 589681. [CrossRef]

93. Wang, M.; Xia, C.; Huang, L.; Xu, S.; Qin, C.; Liu, J.; Cao, Y.; Yu, P.; Zhu, T.; Zhu, H.; et al. Deep learning-based triage and analysis of lesion burden for COVID-19: A retrospective study with external validation. Lancet Digit. Health 2020, 2, e506-e515. [CrossRef]

94. Bird, J.J.; Barnes, C.M.; Premebida, C.; Ekárt, A.; Faria, D.R. Country-level pandemic risk and preparedness classification based on COVID-19 data: A machine learning approach. PLoS ONE 2020, 15, e0241332. [CrossRef]

95. Etzioni, E.; Decario, N. AICan Help Scientists Find a Covid-19 Vaccine. Wired. 28 March 2020. Available online: https://www.wired.com/story/opinion-ai-can-help-find-scientists-find-a-covid-19-vaccine/ (accessed on 28 March 2020).

96. LitCOVID. 2020. Available online: https://www.ncbi.nlm.nih.gov/research/coronavirus/ (accessed on 15 May 2020).

97. Soam, S.S.; Bhasker, B.; Mishra, B.N. Improved prediction of MHC class I binders/non-binders peptides through artificial neural network using variable learning rate: SARS corona virus, a case study. Adv. Exp. Med. Biol. 2011, 696, 223-229. [CrossRef]

98. Khan, A.; Ali, S.S.; Khan, M.T.; Saleem, S.; Ali, A.; Suleman, M.; Babar, Z.; Shafiq, A.; Khan, M.; Wei, D.Q. Combined drug repurposing and virtual screening strategies with molecular dynamics simulation identified potent inhibitors for SARS-CoV-2 main protease (3CLpro). J. Biomol. Struct. Dyn. 2020, 1-12. [CrossRef]

99. Hage-Melim, L.; Federico, L.B.; de Oliveira, N.K.S.; Francisco, V.C.C.; Correia, L.C.; de Lima, H.B.; Gomes, S.Q.; Barcelos, M.P.; Francischini, I.A.G.; da Silva, C. Virtual screening, ADME/Tox predictions and the drug repurposing concept for future use of old drugs against the COVID-19. Life Sci. 2020, 256, 117963. [CrossRef] [PubMed]

100. De Oliveira, O.V.; Rocha, G.B.; Paluch, A.S.; Costa, L.T. Repurposing approved drugs as inhibitors of SARS-CoV-2 S-protein from molecular modeling and virtual screening. J. Biomol. Struct. Dyn. 2020, 1-10. [CrossRef] [PubMed]

101. Stebbing, J.; Krishnan, V.; de Bono, S.; Ottaviani, S.; Casalini, G.; Richardson, P.J.; Monteil, V.; Lauschke, V.M.; Mirazimi, A.; Youhanna, S.; et al. Mechanism of baricitinib supports artificial intelligence-predicted testing in COVID-19 patients. EMBO Mol. Med. 2020, 12, e12697. [CrossRef] [PubMed]

102. Metz, C. How AI streered doctors towards possible coronavirus treatment. The New York Times, 30 April 2020.

103. NIH Clinical Trial of Investigational Vaccine for COVID-19 Begins NIH. 2020. Available online: https://www. nih.gov/news-events/news-releases/nih-clinical-trial-investigational-vaccine-covid-19-begins (accessed on 15 May 2020).

104. Yang, X.; Wang, Y.; Byrne, R.; Schneider, G.; Yang, S. Concepts of Artificial Intelligence for Computer-Assisted Drug Discovery. Chem. Rev. 2019, 119, 10520-10594. [CrossRef]

105. Asai, A.; Konno, M.; Ozaki, M.; Otsuka, C.; Vecchione, A.; Arai, T.; Kitagawa, T.; Ofusa, K.; Yabumoto, M.; Hirotsu, T.; et al. COVID-19 Drug Discovery Using Intensive Approaches. Int. J. Mol. Sci. 2020, 21, 2839. [CrossRef] [PubMed]

106. Yong, E. A Popular Algorithm Is No Better at Predicting Crimes Than Random People. The Atlantic, 17 January 2018.

107. Souza Filho, E.M.; Fernandes, F.A.; Soares, C.L.A.; Seixas, F.L.; Santos, A.; Gismondi, R.A.; Mesquita, E.T.; Mesquita, C.T. Artificial Intelligence in Cardiology: Concepts, Tools and Challenges—“The Horse is the One Who Runs, You Must Be the Jockey". Arq. Bras. Cardiol. 2019. [CrossRef]

108. Gurupur, V.; Wan, T.T.H. Inherent Bias in Artificial Intelligence-Based Decision Support Systems for Healthcare. Medicina 2020, 56, 141. [CrossRef] 
109. Randhawa, G.K.; Jackson, M. The role of artificial intelligence in learning and professional development for healthcare professionals. Healthc. Manag. Forum 2020, 33, 19-24. [CrossRef]

110. Asan, O.; Bayrak, A.E.; Choudhury, A. Artificial Intelligence and Human Trust in Healthcare: Focus on Clinicians. J. Med. Internet Res. 2020, 22, e15154. [CrossRef]

Publisher's Note: MDPI stays neutral with regard to jurisdictional claims in published maps and institutional affiliations.

(C) 2020 by the authors. Licensee MDPI, Basel, Switzerland. This article is an open access article distributed under the terms and conditions of the Creative Commons Attribution (CC BY) license (http://creativecommons.org/licenses/by/4.0/). 